on their first screening later developed chronic simple glaucoma. This is further evidence against the view that lowered outflow, raised tension, disc cupping, and finally field loss is the sequence of events in the development of this disease. It would seem that the majority of patients with glaucoma develop raised tension followed by cupping; some develop cupping before raised tension; and another minority develop both at the same time. It is difficult to avoid the conclusion that a common factor underlies both cupping and ocular hypertension, probably operating at different loci but not necessarily simultaneously or in a set order. 8

\footnotetext{
1 Bankes, J. L. K., Perkins, E. S., Tsolakis, S., and Wright, J. E., British Medical Fournal. 1968, 1, 791.

2 Perkins, E. S., British fournal of Ophthalmology, 1973, 57, 179.

Perkins, E. S., British fournal of Ophthalmology, 1973, $57,179$.

Perkins, E. S., Atti Societa Ottalmologica Italiana, 1967, 24, 181

Goldmann, H., American fournal of Ophthalmology, 1959, 48, 213.

- Goldmann, H., American fournal of Ophthalmology, 1959, 48, 213.

? Mrance, S. M., British Fournal of Ophthalmology, 1972, 56, 186.

${ }^{7}$ Miller, S. J. H., British Fournal of Ophthalmology, 1972a, 56, 284. Killer, S. J. H., Transactions
}

\section{Detection of Biliary Tract Disease at Operation}

Various methods are available for detecting disease of the common bile duct at operation. Many surgeons probably rely on the findings at operation together with the patient's history. But the evidence shows that these methods are not in themselves enough. Stones may be missed, and unnecessary choledochotomies may be performed.1-3 Operative cholangiography is now widely carried out, for as well as adding to the accuracy of diagnosis it provides a permanent record which may be of help in the future management of the patient. The image intensifier will probably further improve operative cholangiograms. Preoperative intravenous cholangiography is not a reliable substitute for operative cholangiography.

Fibreoptic choledochoscopes have been available for some years. Though they have found favour on the Continent of Europe, they have not been so popular for routine use in Great Britain. Another procedure that has been undertaken in Europe is manometry of the bile ducts, but this too is little used in Britain. Recently a detailed study of the results obtained with it on 218 patients has been reported from Wales. ${ }^{4}$ The procedure is said to be safe, simple, and less time-consuming than operative cholangiography and to give results that justify more widespread use.

Manometry of the bile ducts is used to determine, firstly, the opening pressure of the sphincter of Oddi, that is, the pressure of saline necessary to produce a continuous steady flow of saline into the common duct; and, secondly, the volume of saline that can be introduced into the duct per minute at various heads of pressure. When these data are compared with those obtained in a model duct system the diameter of the ampulla of Vater can be calculated.

Gallstones anywhere in the duct system are believed to be associated with a raised opening pressure. An opening pressure of less than $16 \mathrm{~cm}$ of water is regarded as normal. An opening pressure of more than $30 \mathrm{~cm}$ of water is evidence of stones in the common duct or an obstruction at the lower end. Though ducts with an opening pressure of less than 16 $\mathrm{cm}$ of saline are stated to be normal, it is not clear precisely what criteria are used to confirm this. For example, did all of these patients have a normal cholangiogram to support this? About 30 patients in this series had pressures ranging from 16 to $30 \mathrm{~cm}$ of saline. In these cases the opening pressures are equivocal, and presumably cholangiography is needed in such circumstances to exclude duct lesions. As to diagnosis of stenosis of the ampulla of Vater, some critics might need more convincing. The size of the ampulla deduced from the flow data was confirmed by the passage of Bakes dilators, but the accuracy in this assessment of ampullary size may be questioned. Do different surgeons produce the same answer in a particular patient, or is there a significant observer error? Exponents of manometry advocate its use in assessment of the common duct after choledochotomy. But in $12 \%$ of patients examined in this way a persistently high opening pressure was recorded for which no pathological cause could be found. Nor is it clear whether bile duct manometry really is quicker than operative cholangiography.

In summary, it may well be that bile duct manometry is worthwhile, but further evidence would be welcome. Surgeons have been slow to adopt routine operative cholangioraphy despite the overwhelming evidence in its favour. They will require a clear demonstration that bile duct manometry adds to or improves on the information derived from a properly performed operative cholangiogram before abandoning it. A prospective controlled trial would settle this matter.

\footnotetext{
1 Havard, C., Annals of the Royal College of Surgeons of England, 1960, 26,

2 Le Quesne, L. A., Proceedings of the Royal Society of Medicine, 1960, 53,

852.
3 Kako, G. S., Tompkins, R. K., Turnipseed, W., and Zollinger, R., Archives of Surgery, 1972, 104, 484. Daniel, O., Annals of the Royal College of Surgeons of England, 1972, 51,
357.
}

\section{Medicine in Old Age}

Geriatricians sometimes complain about the phrase, "We're all geriatricians nowadays," used by their colleagues in general medicine and surgery. Yet this flippant remark refers only to the average age of patients in most general wards and certainly does not challenge the legitimacy of geriatrics as a specialty in its own right. Indeed, the rapid development of geriatrics has been a particularly British feature, and factors such as full-time consultants, day hospitals, and university departments in the specialty have done much to convert mere existence into a full life for many patients in this age group. The forthcoming reorganization of the Health Service may spread full community care for the old more evenly over the whole country, and hence it is appropriate to consider recent developments in geriatrics. This week we begin a new series 'of "Medical Practice" articles on "Medicine in Old Age," designed to cover important aspects of geriatric care for the non-specialist reader. We hope that these will be found a useful introduction to an important subject.

\section{Industrial Action and the B.M.J.}

The B.M.f. is among those publications affected by continuing industrial action. We regret the inconvenience caused to our readers. 